\title{
Quantitative Characteristics of the Okra [Abelmoschus esculentus (L.) Moench] Root System Under Water Constraints
}

\author{
Rasmata Nana, PhD \\ Badoua Badiel, PhD
}

Université Joseph KI-ZERBO, Laboratoire Biosciences, Equipe

Ecophysiologie Végétale Ouagadougou, Burkina Faso

\section{Hamed Mahamadi Ouedraogo, PhD}

Université Joseph KI-ZERBO, Laboratoire Biosciences, Equipe Génétique et

Amélioration des Plantes, Ouagadougou, Burkina Faso

Frederic Soubande, Tech.

Ministère de l'Agriculture et des Aménagements Hydro-Agricoles

Zoumbiesse Tamini, Prof.

Université Joseph KI-ZERBO, Laboratoire Biosciences, Equipe

Ecophysiologie Végétale Ouagadougou, Burkina Faso

\section{Doi:10.19044/esj.2019.v15n27p159 URL:http://dx.doi.org/10.19044/esj.2019.v15n27p159}

\begin{abstract}
The depth and density of roots play a determining role in the maintenance of the water supply of the plant in a condition of water deficit in the soil. Under water deficit conditions, a root system developing deep in the soil is the most desired character. This study aims to determine adaptive performance of the okra root system under water stress. Thus, the effects of water deficit induced by restriction of soil field capacity (SFC) to $60 \%, 40 \%$ and $20 \%$ were studied in two varieties of okra (V1 and V2) and compared to a control water regime ( $100 \%$ SFC irrigation). Results showed that the number of primary roots, the root volume, the root dry matter, the length of the main root and the root fineness varied according to varieties, water regimes and their interaction. However, varietal differences were observed for the characters length of the main root and root fineness. In addition, a significant difference and very highly significant were respectively observed for the interaction * variety hydric regime on the number of primary roots $(p=0.016)$ and the length of the main root $(\mathrm{p} \leq 0.001)$. Under water regimes at $60 \% \mathrm{SFC}$, $40 \%$ SFC or $20 \%$ SFC, there is an increase in length of the main root of the varietyV2; but for the variety V1, the increase was noted in the plants irrigated
\end{abstract}


at $40 \%$ SFC. On the other hand, in both varieties, root fineness increased under all restrictive water regimes.

Keywords: Okra, Varieties, Water regime, Roots, Characters

\section{Introduction}

In Burkina Faso, agriculture is the main source of economic and social growth. It constitutes the essential sector of jobs because it employs more than $86 \%$ of the active population, contributes for more than $40 \%$ to the Gross Domestic Product (GDP) (MASA, 2013). However, despite the potential of the country and the efforts made by the various governments to satisfy the population's food demand and ensure sustainable food security, to date Burkina Faso is still far from achieving food self-sufficiency. This is mainly due to low crop productivity which is not consistent with the exponential growth of the population. Other factors explain this situation, particularly the deterioration of climatic conditions, which most often exposes cultivated species to recurrent water deficit. Among the affected crop species, there is Okra of the genus Abelmoschus, a plant neglected and marginalized by research and agricultural structures in Burkina Faso (Ouédraogo et al., 2016 ; Sawadogo et al., 2009); and the challenge of its production is also poorly perceived because of its marginalization in relation to cereal crops (Nana, 2005). Nevertheless, okra is one of the most important vegetable crops in the tropics and subtropics, where it plays a key role in the financial equilibrium of peri-urban farming systems (Tshomba et al., 2015).In Burkina Faso, okra plays a significant socio-economic role through its use in food and the generation of financial resources for producers. There is certainly a craze for its production in rural and peri-urban Burkina Faso, but its culture remains low because of climatic constraints characterized by a great heterogeneity of drought forms. Studies on the agro-morphological and physiological characterization of okra have already been carried out (Sani et al., 2019); but the characteristics of the root system of okra related to his resistance to water stress are unknown. Indeed, the absorption and transport of water and mineral elements to the aerial parts of the plant depends on the root system. In addition, the water absorption depends on the number of roots occupying the soil volume, the size and length of roots, the distance that water must travel in the roots of the absorption site up to at the site of use, the age of roots and the rate of new roots produced (Maynard et David, 1987). The overall objective of this work was to understand the adaptive response of okra root system to water constraint. Specifically, it was to determine characteristics of the okra root system under water deficit conditions and to identify okra variety with deep root development under water stress. 


\section{Material and methods \\ Plant material}

Two varieties of okra called V1 and V2 were used for this study. The choice of these varieties is justified by the insufficiency of data on their morpho-physiological characteristics under conditions of water stress.

\section{Determination of the soil field capacity}

The soil field capacity (SFC) corresponds to the quantity of water retained, after 48 hours of free water dripping to the water table, by a soil previously saturated with water. It has been evaluated to determine water quantities to bring by watering and pot according water treatments. For this, 3 soil samples (substrate) of culture were dried and then weighed and the dry weights DW-S1, DW-S2, DW-S3 noted. These samples were then watered to saturation, then pots were covered with plastics to avoid evaporation and let drain to the cleaning point for 48 hours. Soil samples were weighed again and their saturation weights SW-S1, SW-S2, SW-S3 noted. The soil field capacity was calculated for each sample by the following formula:

$$
\boldsymbol{S F C}=\frac{\boldsymbol{S} \boldsymbol{W} \boldsymbol{D} \boldsymbol{W}}{\boldsymbol{D} \boldsymbol{W}} \text { in } g \text { of water by } g \text { of dry earth }
$$

The average of the SFC was calculated by summing SFC of different soil samples divided by the number of samples.

\section{Experimental design and test conduct}

Plants were grown in pots; arranged in three randomized blocks. A total of 72 pots ( 3 pots $x 2$ varieties $x 4$ water treatments $x 3$ blocks) were used for the test. Each block was subdivided into four sub-blocks or crop plots corresponding to the different water treatments. Each plot of culture had six pots with three pots per variety.

The sowing was carried out on March 16, 2019 with three seeds per pot, each containing $17 \mathrm{~kg}$ of soil. Unmarking was done two weeks after planting, leaving two plants per pot and another Unmarking at 21 days after sowing (DAS) at one plant per pot, followed by the start of water regimes application. Four water regimes were tested: a water regime at $100 \%$ of the soil field capacity (SFC), a 60\% SFC water regime, a 40\% SFC water regime and a $20 \%$ SFC water regime. Thus, water quantities supplied per pot and irrigation were 4.25 liters for the $100 \%$ SFC water regime (S0), 2.55 liters, 1.70 liters and 0.85 liters respectively for the water regimes at $60 \% \mathrm{SFC}(\mathrm{S} 1)$, $40 \%$ SFC (S2) and 20\% SFC (S3). Weeding was done manually on demand. The plants were grown under natural conditions of illumination, temperature and hygrometry. During the test, the average daily temperature recorded in the laboratory varied between $28.20^{\circ} \mathrm{C}$ and $30.70^{\circ} \mathrm{C}$; and the relative humidity ranged from $69.67 \%$ to $78.33 \%$. 


\section{Measured parameters}

Parameters were quantitative and were obtained by biometric field and / or laboratory measurements. The measures concerned :

* Leaves fall (LF): it was evaluated by manual counting of the number of leaves that fell during the period of water stress;

* Characteristics of the root system: they were evaluated at the end of the water stress after 45 days of application, ie at the $66^{\text {th }}$ days after sowing (DAS). To do this, the soil was separated from roots by a jet of tap water. The roots were then washed in a tank before taking measurements. Parameters of rooting evaluated are as follows:

$\checkmark$ Number of primary roots (NPR), determined by counting root lengths measuring at least $2 \mathrm{~cm}$;

$\checkmark$ Length of the main root (LMR), was measured in centimeters (cm) using a graduated ruler

$\checkmark$ Root volume (RV), expressed in $\mathrm{cm}^{3}$, was evaluated according to the method of Musick et al., (1965) by comparing the water levels, before and after immersion of all roots in a known volume of water;

$\checkmark$ Dry root mass (DRM), expressed in gram (g), was determined after drying in an oven at $60^{\circ} \mathrm{C}$ for 96 hours using the method of Heitholt (1989);

$\checkmark$ Root fineness (RF), expressed in $\mathrm{cm} / \mathrm{g}$ dry matter, was evaluated by the ratio of root length to dry root weight according to the method of Wilhelm et al., (1982).

\section{Data analysis}

Data were the subject of graphs with the Excel spreadsheet version 2007. The effect of the water regime on the characters of the root system was appreciated through an Analysis of Variance (ANOVA) using the software XLSTAT version 2016.02.27444. The Dunnett (bilateral) test for comparison of averages was performed at $5 \%$ threshold.

\section{Results}

\section{Soil water content}

At the last day, the soil water content (SWC) showed that the water stress induced by reduction of the soil field capacity, caused a gradual decrease of this parameter according to the water regimes (figure 1). Soil of the water regime $\mathrm{S} 0$ recorded the highest moisture content with an average of $12.63 \%$ followed by regimes S1 and S2 (9.26\%) and the water regime S3 (5.46\%). 


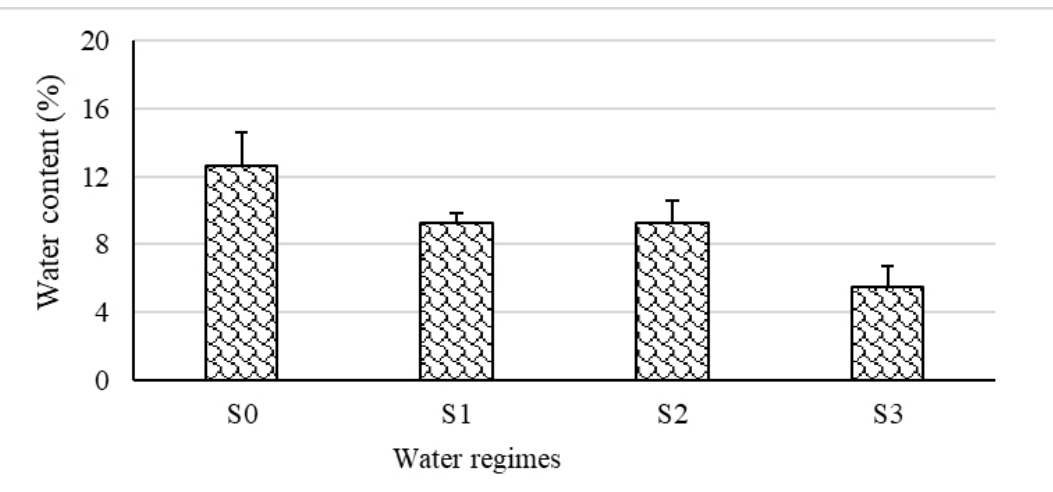

Figure 1 :Soil water content on the last day of water stress according to water treatments Legend : SO :plants watered at 100\% SFC;:S1: plants watered at 60\% SFC, S2: plants watered at $40 \%$ SFC, S3: plants watered at $20 \%$ SFC.

\section{Leaf fall}

Results showed that the leaf fall was variable depending on the water regimes applied to the plants. Indeed, the fall of leaves has been observed only in plants subjected to deficient water regimes S2 and S3 (Figure 2). Plants of water treatment $S 3$ recorded a higher leaf fall with an average of $4.16 \pm$ add the Ecart type of mean leaves per plant in the variety V1 and $3.66 \pm$ add the Ecart type of mean leaves per plant for the variety V2. Analysis of variance revealed no significant difference $(\mathrm{p}=0.153)$ between varieties (Table 1$)$. On the other hand, the difference between control (S0) and water treatments $\mathrm{S} 3$ and S2 was significant.

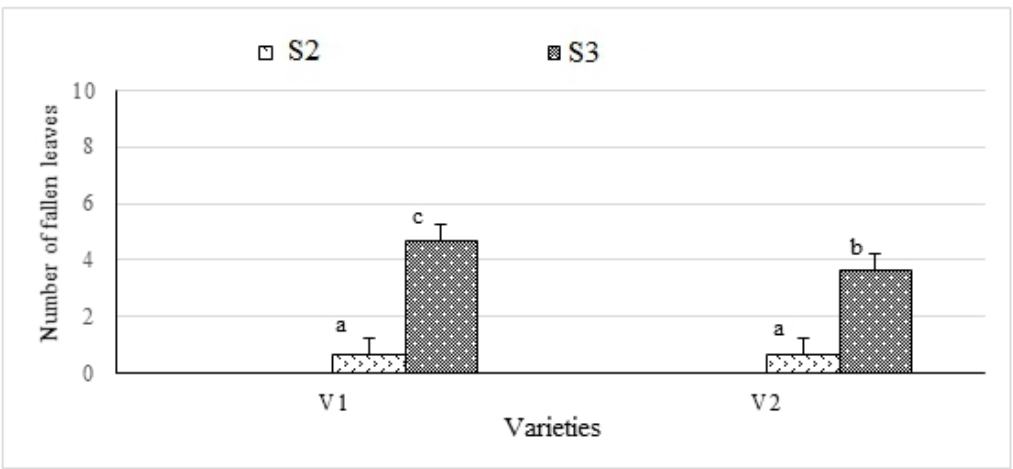

Figure 2 : Interactions variety*water regime on leaf fall 
Table 1: Analysis of the differences between Varieties modalities; the control modality Water regime-SO and the other modalities with a 95\% confidence interval on the leaf fall

\begin{tabular}{lll}
\hline Varieties and water regimes & $\mathbf{P}$ & Significant \\
\hline V2 vs V1 & 0.153 & $\mathrm{~ns}$ \\
S0 vs S3 & $<\mathbf{0 , 0 0 0 1}$ & $* * *$ \\
S0 vs S2 & $\mathbf{0 . 0 3 1}$ & $*$ \\
S0 vs S1 & 1.000 & $\mathrm{~ns}$ \\
\hline
\end{tabular}

Legend:S0: plants watered at 100\% SFC, S1 : plants watered at 60\% SFC, S2 : plants watered at $40 \%$ SFC, $\mathbf{S 3}$ : plants watered at 20\% SFC, P: Probability ; ns : not significant difference; $*$ : significant difference $; * * *$ :very highly significant difference at $5 \%$ threshold.

\section{Number of primary roots}

The number of primary roots (NPR) emitted by plants was variable according to the water regime and the variety (Figure 3). Indeed, the two varieties of okra recorded a higher number of primary roots under the water treatment S2, with respectively an average of $45.66 \pm$ add the Ecart type of mean and $44.66 \pm$ add the Ecart type of mean primary roots. In general, the water regime S2 (40\% SFC) had a stimulating effect on the primary root formation of both varieties, whereas the water regime S3 (20\% SFC) had a more reducing effect on the number of primary roots. However, the analysis of variance revealed no significant difference $(\mathrm{p}=0.829)$ between V1 and V2 (Table 2). However, there was a significant difference between water treatments; with a water regime S3 (20\% SFC) which differs from regimes S0 $(\mathrm{p}=0.015)$ in the number of main roots. The interaction between variety and water regime was statistically significant (Figure 3 ).

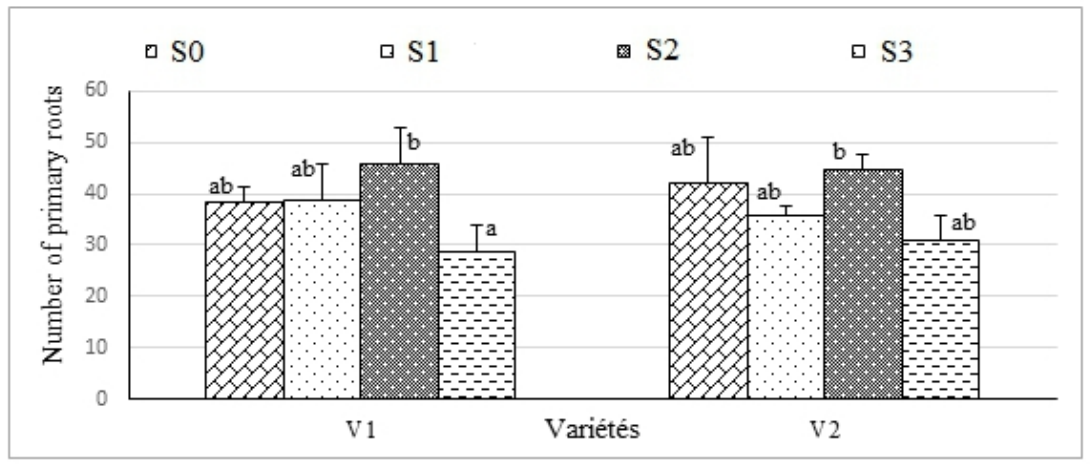

Figure 3: Interactions variety*water regime on the number of primary roots 
Table 2: Analysis of the differences between varieties modalities; the control modality Water regime-SO and the other modalities with a 95\% confidence interval on the number of primary roots.

\begin{tabular}{lll}
\hline Varieties and water regimes & $\mathbf{P}$ & Significant \\
\hline V1 vs V2 & 0,829 & $\mathrm{~ns}$ \\
& & \\
S0 vs S3 & $\mathbf{0 . 0 1 5}$ & $*$ \\
S0 vs S1 & 0.680 & $\mathrm{~ns}$ \\
S0 vs S2 & 0.311 & $\mathrm{~ns}$ \\
\hline
\end{tabular}

Legend:S0: plants watered at 100\% SFC, S1 : plants watered at 60\% SFC, S2 : plants watered at $40 \%$ SFC, S3 : plants watered at 20\% SFC, P: Probability ; ns : not significant difference; * : significant difference ; at $5 \%$ threshold.

\section{Root volume}

The two varieties of okra are distinguished by a large variation in root volume under water deficit conditions. Indeed, under the deficient water regimes S1 (60\% SFC) S2 (40\% SFC) and S3 (20\% SFC), there was an increase in the roots volume of the variety V2 with respectively $43.33 \mathrm{~cm}^{3} \pm$ add the Ecart type of mean, $46.66 \mathrm{~cm}^{3} \pm$ add the Ecart type of mean, $33.33 \mathrm{~cm}^{3}$ \pm add the Ecart type of mean against $26.66 \mathrm{~cm}^{3} \pm$ add the Ecart type of mean for the control (S0) (figure 4). On the other hand, the increase was only observed in the variety V1 under the water regime S2. Analysis of variance revealed no significant difference between the two varieties (Table 3) and between control regime $\mathrm{S} 0$ and the other water treatments.

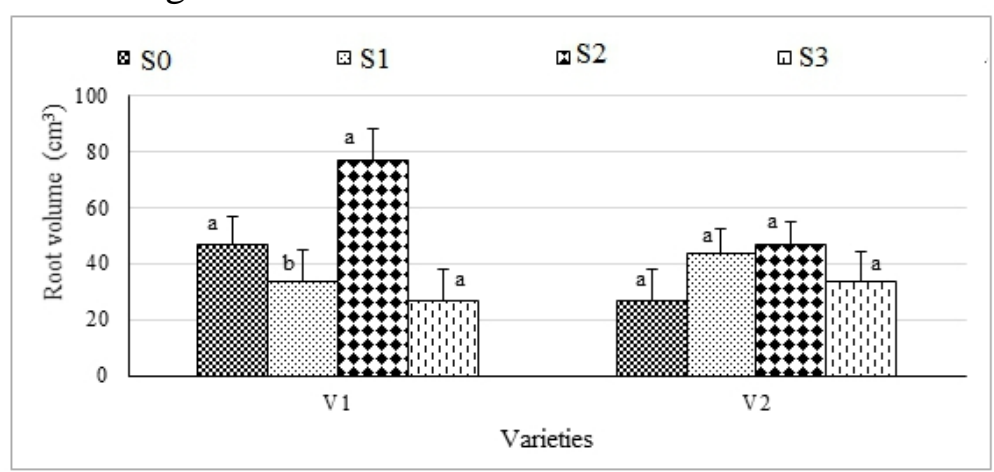

Figure 4: Interactions variety*water regime on root volume

Tableau 3: Analysis of the differences between varieties modalities; the control modality Water regime-SO and the other modalities with a 95\% confidence interval for root volume

\begin{tabular}{lll}
\hline Varieties and water regimes & $\mathbf{P}$ & Significant \\
\hline V1 vs V2 & 0.250 & $\mathrm{~ns}$ \\
& & $\mathrm{~ns}$
\end{tabular}


S0 vs S2

0.056

ns

S0 vs S1

0.996

ns

Legend: S0: plants watered at 100\% SFC, S1 : plants watered at 60\% SFC, S2 : plants watered at $40 \%$ SFC, $\mathbf{S 3}$ : plants watered at $20 \%$ SFC, P: Probability ; ns : not significant difference at $5 \%$ threshold.

\section{Dry mass of roots}

Under the effect of the different water regimes, the root dry mass was variable between varieties but also between treatments. Thus, water regimes S1 and S3 caused a reduction in root dry weight of the variety V1 (Figure 5). However, in the variety V2, the dry mass of roots increased slightly when plants were irrigated to $60 \%$ (S1) or $40 \%$ (S2) of the soil field capacity. Results of the analysis of variance revealed no significant difference $(p=0.176)$ between varieties (Table 4). In addition, water regimes S1, S2 and S3 were not significantly different from the control water regime $\mathrm{S} 0$ for root dry weight.

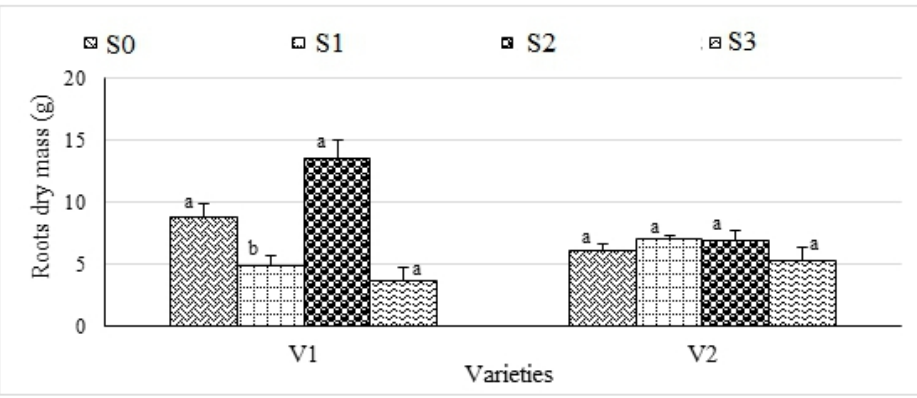

Figure 5: Interactions variety*water regime on root dry mass

Table 4: Analysis of the differences between modalities varieties; the control modality Water regime-SO and the other modalities with a 95 confidence interval for root dry mass

\begin{tabular}{lll}
\hline $\begin{array}{l}\text { Varieties and water regimes } \\
\text { V2 vs V1 }\end{array}$ & $\mathbf{P}$ & $\begin{array}{l}\text { Significant } \\
\mathrm{ns}\end{array}$ \\
& 0.176 & $\mathrm{~ns}$ \\
S0 vs S3 & 0.117 & $\mathrm{~ns}$ \\
S0 vs S1 & 0.616 & $\mathrm{~ns}$ \\
S0 vs S2 & 0.132 & .
\end{tabular}

Legend:S0: plants watered at 100\% SFC, S1 : plants watered at 60\% SFC, S2 : plants watered at $40 \%$ SFC, $\mathbf{S 3}$ : plants watered at $20 \%$ SFC, P: Probability ; ns : not significant difference at $5 \%$ threshold.

\section{Length of the main root}

The length of the main root (LRP) of the variety V1 was reduced under deficient water regimes $\mathrm{S} 1, \mathrm{~S} 2$ and $\mathrm{S} 3$; while under these same water regimes, the main root of the variety V2 recorded an increase in its length (Figure 6). 
Indeed, the length of the main root of the variety V1 of treatments S1, S2 and $\mathrm{S} 3$ was on average $52 \mathrm{~cm} \pm$ add the Ecart type of mean, $75 \mathrm{~cm} \pm$ add the Ecart type of mean and $35 \mathrm{~cm} \pm$ add the Ecart type of mean, compared to $82 \mathrm{~cm} \pm$ add the Ecart type of mean for the length of control plants (S0). In the variety $\mathrm{V} 2$, it was $29.33 \mathrm{~cm} \pm$ add the Ecart type of mean in the control plants (S0), $38 \mathrm{~cm} \pm$ add the Ecart type of mean in the treatment plants $\mathrm{S} 1,49.66 \mathrm{~cm} \pm$ add the Ecart type of mean in the treatment plants $\mathrm{S} 2$ and $45.33 \mathrm{~cm} \pm$ add the Ecart type of mean in the treatment plants S3. The results of the analysis of variance indicated a highly significant difference at the $5 \%$ threshold between the two varieties of okra $(\mathrm{p}=0.001)$ for the length of the main root (Table 5). However, the differences between water regime modalities were not significant.

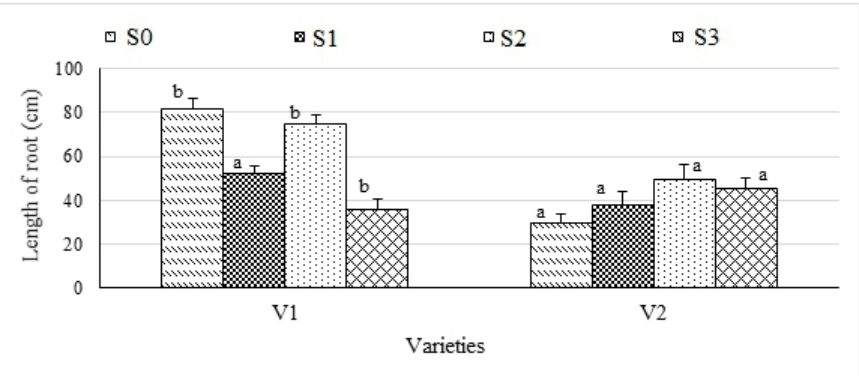

Figure 6 : Interactions variety * water regime along the length of the main root

Table 5: Analysis of differences between varieties modalities; the control modality Water regime-SO and the other water treatments modalities with a 95\% confidence interval for the length of the main root

\begin{tabular}{ccc}
\hline Varieties and water regimes & $\mathbf{P}$ & Significant \\
\hline V2 vs V1 & $\mathbf{0 . 0 0 1}$ & $* *$ \\
& & $\mathrm{~ns}$ \\
S0 vs S3 & 0.095 & $\mathrm{~ns}$ \\
S0 vs S1 & 0.296 & $\mathrm{~ns}$ \\
S0 vs S2 & 0.641 & \\
\hline
\end{tabular}

Legend: S0: plants watered at 100\% SFC, S1 : plants watered at $60 \%$ SFC, S2 : plants watered at $40 \%$ SFC, S3 : plants watered at $20 \%$ SFC, P: Probability ; ns : not significant difference at $5 \%$ threshold.

\section{Root fineness}

Varieties showed variable root fineness depending water regimes. In the variety V2, root finesse increased progressively with decreasing soil field capacity (Figure 7). In addition, in the variety V1, the increase of the root fineness was observed on plants irrigated at $60 \%$ SFC (S1) or $20 \%$ SFC (S3). Analysis of variance showed a significant difference between V1 and V2 ( $\mathrm{p}=$ 0.029 ) for root fineness (Table 6). On the other hand, no significant difference 
was noted between water treatments. The interaction between variety and water regime was statistically insignificant (Figure 7).

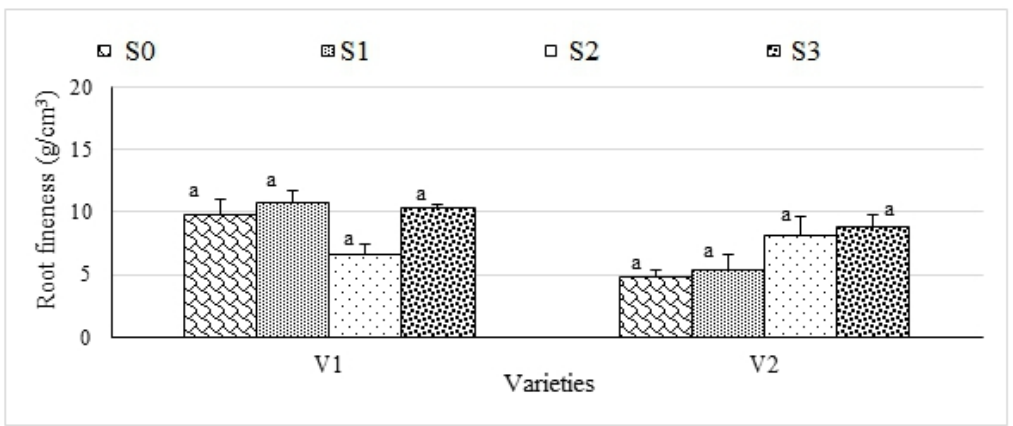

Figure 7: Interactions variety * water regime on root fineness

Table 6 : Analysis of the differences between varieties modalities the control modality Water regime-SO and the other modalities with a 95 confidence interval on root fineness

\begin{tabular}{ccc}
\hline Water regimes & $\mathbf{P}$ & Significant \\
\hline V2 vs V1 & $\mathbf{0 . 0 2 9}$ & $*$ \\
& & \\
S0 vs S3 & 0.340 & $\mathrm{~ns}$ \\
S0 vs S1 & 0.921 & $\mathrm{~ns}$ \\
S0 vs S2 & 1.000 & $\mathrm{~ns}$ \\
\hline
\end{tabular}

Legend: S0: plants watered at 100\% SFC, S1 : plants watered at 60\% SFC, S2 : plants watered at $40 \%$ SFC, S3 : plants watered at 20\% SFC, P: Probability ; ns : not significant difference at $5 \%$ threshold.

\section{Discussion}

In view of results obtained, the effect of water regimes on plants of the two varieties of okra from the $21^{\text {st }}$ DAS to the $66^{\text {th }}$ DAS was variable according to parameters measured. Thus, the water deficit induced by irrigation at $40 \%$ SFC or $20 \%$ SFC caused yellowing of the basal leaves of plants and subsequently their fall. This leaf loss could be an alternative for seedlings to reduce the transpiring surface through the number of leaves. In addition, the number of primary roots (NPR) of varieties of okra was reduced when plants were irrigated at $20 \%$ of the soil field capacity (S3). On the other hand, when the water restriction was carried out at $40 \%$ SFC, plants of the varieties have seen an increase in the number of their primary roots. Water restriction at $20 \%$ SFC seems to cause a more pronounced water deficit. Daaloul et al. (2002) found that in some wheat varieties, the number of primary roots is reduced about $40 \%$ under water deficit conditions, and that the maintenance of high primary root numbers under water stress in other varieties allows better 
accessibility to the water of the plant. In both varieties studied, the restriction water deficit at 60\% SFC (S1), 40\% SFC (S2) and 20\% SFC (S3) positively affects the root volume $(\mathrm{RV})$ of the variety $\mathrm{V} 2$ while in the variety $\mathrm{V} 1$, the increase in root volume was recorded under the regime S3. Indeed, the root volume reflects an extension and / or branching of the root system that favors the colonization of a larger volume of soil, making the soil's water (and nutrient) reserves more accessible to the soil (Benlaribi et al. 1990). The increase in the root volume of the variety V2 under water stress is probably related to the increase in the length of its main root under water stress. Indeed, El Fakhri et al., (2010), found a positive correlation between the length of the main root, the number of primary roots and the root volume in wheat varieties. The characteristics expressed by the variety V2 seem to have a genetic origin. Under different water restrictions, the variety V2 tends to accumulate more dry matter in its roots than the variety V1. According to Daaloul et al. (2002), the most important characteristic is not the quantity of dry matter accumulated in the roots but their destination. Thus, this dry matter is used for the production of new roots, their proliferation (root volume), their elongation (increase in length) and their maintenance (El Fakhri et al., 2010). Low translocation of photo-assimilates causes a decrease in root mass. Under water deficit, the variety V2 seems to be more consuming photo-assimilates by orienting them more towards the roots, which would be at the origin of the increase the root dry mass.

In addition, under the three restrictive water regimes $60 \% \mathrm{SFC}(\mathrm{S} 1)$, $40 \%$ SFC (S2) and 20\% SFC (S3), the variety V2 was successful in terms of increasing the length of the main root ( LMR). When the water conditions are favorable, there may be a balance between the different root parameters with a tendency to elongation(El Fakhri et $a l ., 2010)$. Also, the increase of the LMR under water deficit would be an interesting characteristic to facilitate deep soil exploration.Indeed, this increase indicates a deep rooting process that makes it possible to draw water at depth when it is limited in the upper layers of the soil (Brown et al., 1985); and even if this depth is reached only by a single main root (Dib et $a l$., 1992). Our results seem to corroborate those of Sayar et al. (2008) who showed that the water deficit applied to durum wheat at the $1 / 3$ SFC irrigation dose causes a reduction in the number of primary roots.

The root fineness increased progressively with the decrease in soil field capacity (S1, S2, S3) in the variety V2; but this increase has been observed in plants of the variety V1 in water treatments S1 or S3.The root finesse seems to be an important characteristic because it allows a better adaptation of the plant to the hydric conditions of the environment. The increase in root fineness could be explained by a larger allocation of dry matter for the production of branched roots. The more roots there are, the finer they are that can result from a compensatory effect (Sayar et al., 2008). 


\section{Conclusion}

The results showed a variability in the characters of the okra root system depending on varieties and water regimes. The effect of water deficit on root parameters was a function of the degree of deficit.Indeed, the plants irrigated at $20 \%$ of the soil field capacity (SFC) had a reduced primary root number and reduced root mass in the two varieties. However, an increase in the length of the main root was noted under water regimes at $60 \%$ SFC (S1), $40 \%$ SFC (S2) and 20\% SFC (S3) in the variety V2, but only under the water regime at $40 \% \mathrm{SFC}$ in the variety V1.In addition, under water restrictions $\mathrm{S} 1$, $\mathrm{S} 2$ and $\mathrm{S} 3$, the root fineness increased in the two varieties. The length of the main root (LMR) and root fineness (RF) appear to be the most relevant okra root traits for water stress resistance and can be used as an indicator of tolerance to water stress in okra. In terms of results, the variety V2 would present the best adaptive performance of the root system to the water deficit. This study allows a rational use of these varieties in the Okra improvement programs of Burkina Faso and other countries.

\section{Conflicts of Interest}

The authors declare that there are no conflicts of interest regarding the publication of this paper.

\section{Acknowledgments}

The authors are grateful to members of "Laboratoire Biosciences" and "Multipurpose Agricultural Center of Matourkou" for manuscript correction.

\section{References:}

1. Benlaribi M, Monneveux P, Grignac P. 1990. Etude des caractères d'enracinement et de leur rôle dans l'adaptation au déficit hydrique chez le blé dur (Triticum durum Desf). Agronomie 10:305-322.

2. Brown S.C., Gregory P.J, Wahbi A., 1985. In: J.P. Srivastava, E. Porceddu, E. Acevedo, S. Varma (Eds), Drought tolerance in winter cereals A.. Proceedings of the international workshop, Capri, Italy, 2731.

3. Daaloul A., Bchini H. et Sayar R., 2002. Variabilité génétique de quelques paramètres du système racinaire du blé dur (Triticum durum Desf.) sous deux régimes hydriques. Plant Genet. Newsletter, 129: 2531.

4. Dib A. T., Monneveux P. et Araus J.L., 1992. Adaptation à la sècheresse et notion d'idéotype chez le blé dur II : Caractères physiologiques d'adaptation. Agronomie; 12: 381-393. 
5. El Fakhri M., Mahboub S., Benchekroun M. et Nsarellah N., 2010. Effet du stress hydrique sur les caractéristiques d'enracinement du blé dur (Triticum Durum. Desf) ; Revue Nature et Technologie, 3 :06 - 12

6. Heitholt J.J., 1989. Water use efficiency and dry matter distribution in nitrogen and water stressed winter wheat. Agronomy Journal 81:464469.

7. MASA, 2013. Sécurité alimentaire et résilience des populations : enjeux et défis. $16^{\text {ème }}$ édition de la Journée Nationale du Paysan à Banfora au Burkina, pp16-17.

8. Maynard G.H. et Orcutt D.M., 1987. The physiology of plants under stress. Wiley, New York, USA, pp. 27-43.

9. Musick G.J., Fairchild M.L., Ferguson V.L., Zuber MS. 1965. A method of measuring root volume in corn (Zea mays L). Crop Science, 5:601-602.

10. Nana R, 2005. Influence de la fréquence et de la période d'arrosage sur l'économie d'eau : adaptation physiologique du gombo [Abelmoschus sculentus(L.) Moench] en culture de contre-saison. Memo. DEA, Univ. Ouagadougou, 68 p.

11. Ouédraogo M. H., 2016. Etude de la diversité génétique des gombos [Abelmoschus esculentus(L.) Moench] cultivés au Burkina Faso. Thèse Doctorat, Université Ouaga I Pr KI-ZERBO, p149.

12. Sani I. S., Grema M., Sanjeet K., Yacoubou B. and Mahamane A., 2019. Regeneration an preliminary characterization of Asian and African okra (Abelmoschus spp) germplam. European Scientific Journal, 15(6):21-32.

13. Sawadogo M., Balma D., Nana R. \& Meto-kazileTuosanLiviusSomda R., 2009. Diversité agromorphologique et commercialisation du gombo (Abelmoschus esculentus L.) à Ouagadougou et ses environs. Int. J. chem. Sci. 3(2): 326-336.

14. Tshomba K. J., Esoma O. B., Muyambo M. E., Useni S. Y., and Nyembo K. L., 2015. Facteurs influençant le profit de la culture de gombo dans les conditions pédoclimatiques et socio-économiques de Lubumbashi en RDC ; International Journal of Innovation and Applied Studies, 12 (4) :820-830.

15. Wilhelm W.W., Mielke L.N. and Fewsster C.R., 1982. Root development of winter wheat as related totillage practice in Western Nebraska . Agronomy Journal, 74:85-88. 